\title{
Liver-enriched activator protein I as an isoform of CCAAT/enhancer-binding protein beta suppresses stem cell features of hepatocellular carcinoma
}

This article was published in the following Dove Press journal:

Cancer Management and Research

\author{
Li-Hua Yang ${ }^{1,2, *}$ \\ Ye Wang ${ }^{1,3, *}$ \\ Shi Qiaol,* \\ Min-Jun Wang' \\ Fei Chen' \\ Xiao-Yuan $\mathrm{Zi}^{1}$ \\ Jian-Xiu Li ${ }^{\prime}$ \\ Hai-Bin Zhang ${ }^{4}$ \\ Bing Yu ${ }^{1,4}$ \\ Yi-Ping $\mathrm{Hu}^{\prime}$ \\ 'Department of Cell Biology, \\ Center for Stem Cell and Medicine, \\ Second Military Medical University, \\ Shanghai, People's Republic of China; \\ ${ }^{2}$ Department of Cell Biology and \\ Neurobiology, Xuzhou Medical \\ University, Xuzhou, People's Republic \\ of China; ${ }^{3}$ Department of Urology, \\ Changhai Hospital, Second Military \\ Medical University, Shanghai, People's \\ Republic of China; ${ }^{4}$ Department \\ of Hepatic Surgery V, Eastern \\ Hepatobiliary Surgery Hospital, \\ Shanghai, People's Republic of China \\ *These authors contributed equally to \\ this work
}

Correspondence: Bing Yu; Yi-Ping Hu Department of Cell Biology, Center for Stem Cell and Medicine, Second Military Medical University, 800 Xiang Yin Road, 200433, Shanghai, People's Republic of China

Tel +8621 81870945

Email smmucellyu@I63.com;

yphu@smmu.edu.cn

\begin{abstract}
Purpose: Liver cancer stem cells (CSCs) are known to be associated with the development, survival, proliferation, metastasis, and recurrence of liver tumors. The aim of this study was to investigate the association of liver-enriched activator protein 1 (LAP1) with hepatocellular carcinoma (HCC) and liver CSCs (LCSCs) and explore the impact of LAP1 on LCSCs.

Materials and methods: Differences in LAP1 expression in liver cancer tissues versus matched para-tumoral liver tissues and LCSCs versus non-CSCs were analyzed by Western blotting, real-time polymerase chain reaction, immunohistochemistry, and flow cytometry. The effect of LAP1 on liver cancer cells was evaluated by the expression of CSC markers, oncosphere formation, proliferation, migration, and invasion in vitro. Cell cycle distribution and the number of apoptotic cells were analyzed to assess cell cycle and cell apoptosis. Furthermore, a mouse subcutaneous tumor implant model was established to explore the role of LAP1 in the development of HCC in vivo. Finally, the expression of CSC markers in paraffin-embedded sections was evaluated by immunofluorescence.
\end{abstract}

Results: LAP1 was weakly expressed in HCC tumors and cell lines and even weaker in LCSCs. LAP1 inhibited the expression of stem cell-associated genes and reduced the abilities of oncosphere formation, proliferation, migration, and invasion in vitro. Cell cycle assay revealed that LAP1 induced G1/G0 arrest. Furthermore, LAP1 decreased subcutaneous tumor-formation ability and the expression of CSC markers and Ki67 in vivo.

Conclusion: LAP1 suppressed the stem cell features of HCC, indicating that it possessed an antitumor effect in liver cancer, both in vitro and in vivo; therefore, LAP1 may prove to be a potential target in liver CSC-targeted therapy.

Keywords: LAP1, liver-enriched activator protein 1, hepatocellular carcinoma, HCC, liver cancer stem cell

\section{Introduction}

Hepatocellular carcinoma (HCC) is one of the most common malignancies in the People's Republic of China. Histologically, HCC is the most common type of primary liver cancer, accounting for $85 \%-90 \%$ of all primary liver cancers. ${ }^{1}$ The incidence of liver cancer ranks fifth, and mortality from HCC ranks third among all malignancies. ${ }^{1-3}$ Although continuous progress has been made in the diagnosis and surgical and biological therapies of liver cancer, the overall prognosis of patients with liver cancer remains unsatisfactory due to recurrence, metastasis, chemoresistance, and 
radiation resistance. ${ }^{4}$ Therefore, more efforts are required to explore novel and more effective treatments for liver cancer.

Cancer stem cells (CSCs) play important roles in the development, metastasis, drug resistance, and many other biological processes of tumors. ${ }^{5-7}$ The concept of CSCs was first proposed by Mackillop et al, ${ }^{8}$ who proposed that there may be a small number of cells in cancer that had similar functions as stem cells. In 1997, Bonnet and Dick ${ }^{9}$ identified CD34 ${ }^{+} / \mathrm{CD} 38^{-}$in leukemia as CSCs. Subsequent research further identified CSCs in various solid tumors, including cancers of the breast, lung, prostate, brain, and pancreas. ${ }^{10-13}$ Meanwhile, many studies confirmed that CSCs also exist in HCC and could be enriched by several defined surface markers such as CD133, CD13, CD44, OV6, epithelial cell adhesion molecule (EpCAM), CD24, and CD90. ${ }^{6,14,15}$ According to the CSC theory, CSCs contribute to tumorigenesis, metastasis, recurrence, and chemoresistance through cell symmetry and asymmetric division; ${ }^{16}$ therefore, CSCs could be used as the target in tumor therapy. ${ }^{17,18}$

CCAAT/enhancer-binding protein beta (CEBP $\beta)-a$ liver-enriched transcription factor - contains three isoforms, including two liver-enriched activating protein isoforms, LAP1 and LAP2, and a liver-enriched inhibitory protein isoform called LIP. ${ }^{19} \mathrm{CEBP} \beta$ not only regulates the differentiation, proliferation, and survival of hepatocytes but also plays a critical role in inflammatory response and tumorigenesis. ${ }^{20-22}$ Abnormal expression of CEBP $\beta$ is closely associated with the malignancy of a variety of tumors such as glioma, Wilm's tumor, renal cell tumor, and ovarian cancer. ${ }^{23-25}$ LAP1 - the longest isoform - is the most highly expressed isoform of CEBP $\beta$. LAP1 is implicated in cancer progression. LAP1 was reported to repress migration and invasion of $\mathrm{HCC}$ cells in vitro by binding to the ORM2 promoter and activating its expression. ${ }^{26}$ However, little is known about the function of LAP1 in liver CSCs (LCSCs).

In the present study, we explored the association of LAP1 with HCC and LCSCs and the effect of LAP1 on LCSCs. CEBP $\beta$ and LAP1 were found to be weakly expressed in HCC and even weaker in LCSCs. LAP1 suppressed the expression of marker genes of LCSCs and reduced capacities of oncosphere formation, proliferation, wound healing, migration, and invasion in vitro. More importantly, LAP1 decreased subcutaneous tumorigenicity in vivo. These data suggest that LAP1 could be used as an indicator of the diagnosis and prognosis of HCC and may be developed as a target for liver cancer therapy in the future.

\section{Materials and methods \\ Cell lines and tumor specimens}

Human liver cancer cell lines Huh7, Hep3B, and HepG2 were purchased from the American Type Culture Collection and stored in our laboratory. LM3 was purchased from the Cell Bank of the Type Culture Collection of the Chinese Academy of Sciences. All liver cancer cell lines were maintained in Dulbecco's Modified Eagle's Medium (DMEM) supplemented with $10 \%$ fetal bovine serum (FBS; HyClone), $100 \mathrm{mg} / \mathrm{mL}$ penicillin, and $100 \mathrm{U} / \mathrm{mL}$ streptomycin. The primarily cultured human liver cancer cell line CLC13 from liver cancer samples was kindly provided by Dr Lijian Hui from the Chinese Academy of Sciences (Shanghai, People's Republic of China). ${ }^{27}$ CLC13 cells were cultured in RPMI1640 (HyClone), supplemented with 10\% FBS (Gibco), $110 \mu \mathrm{g} / \mathrm{mL}$ sodium pyruvate, $10 \mu \mathrm{g} / \mathrm{mL}$ insulin, 5.5 $\mu \mathrm{g} / \mathrm{mL}$ transferrin, $40 \mathrm{ng} / \mathrm{mL}$ epidermal growth factor (EGF), and $6.7 \mathrm{ng} / \mathrm{mL}$ sodium selenite (Gibco). The use of CLC13 was approved by the ethical committees of Shanghai Xuhui District Central Hospital and Shanghai East China Hospital. Human liver cancer specimens were obtained from the Eastern Hepatobiliary Surgery Hospital/Institute (Shanghai, People's Republic of China), with written informed consent from the patients and approval from the Institutional Review Board of Shanghai Eastern Hepatobiliary Surgery Hospital.

\section{Western blot}

Tumor cells or tumor tissues were lysed in radio immunoprecipitation assay buffer for Western blotting. The proteins were separated on $10 \%$ SDS-polyacrylamide gel electrophoresis (SDS-PAGE) and electrophoretically transferred onto polyvinylidene difluoride membranes (Millipore), which were then blocked in tris-buffered saline and Tween 20 (TBST) containing $5 \%$ defatted milk for $1 \mathrm{~h}$ at room temperature and incubated with primary antibodies overnight at $4^{\circ} \mathrm{C}$ with mouse anti-tubulin (1:10,000; Proteintech Group, Chicago, IL, USA) and rabbit anti-CEBP $\beta$ (1:1,000; Santa Cruz Biotechnology, Santa Cruz, CA, USA). After being washed with TBST and incubated with either horseradish peroxidase (HRP)-conjugated goat anti-rabbit (1:5,000; Proteintech Group) or HRP-conjugated goat anti-mouse (1:5,000; Proteintech Group) secondary antibody, immune complexes were visualized by using Pierce ${ }^{\mathrm{TM}}$ enhanced chemiluminescent (ECL) Western Blotting Substrate (Thermo Fisher Scientific).

\section{Quantitative real time-PCR (qRT-PCR)}

Total RNA was extracted using TRIzol reagent (Invitrogen, Carlsbad, CA, USA), and reverse transcription was 
undertaken using M-MLV Reverse Transcriptase (Promega, M530A) according to the manufacturer's instructions. Quantitative PCR was conducted using LightCycler 480 (Roche) with SYBR Premix Ex Taq reagent (TaKaRa). All samples were examined in triplicate. Data were normalized to control samples. The primers are shown in Table S1.

\section{Hematoxylin and eosin (H\&E), immunohistochemistry, and immunofluorescence staining}

Paraffin-embedded HCC sections from 14 patients were deparaffinized with xylene and rehydrated. For H\&E staining, the rehydrated sections were stained with $H \& E$ (Sigma-Aldrich). For immunohistochemical (IHC) staining, the rehydrated sections were immersed in citrate buffer ( $\mathrm{pH} \mathrm{6.0)} \mathrm{for} \mathrm{antigen} \mathrm{retrieval} \mathrm{at} 121^{\circ} \mathrm{C}$ for $2 \mathrm{~min}$ and then cooled down to room temperature slowly. The endogenous peroxidase activity was blocked with $3 \%$ hydrogen peroxide $\left(\mathrm{H}_{2} \mathrm{O}_{2}\right)$ for $10 \mathrm{~min}$. Nonspecific binding was blocked with $1 \%$ bovine serum albumin for $20 \mathrm{~min}$ at room temperature. The sections were incubated with rabbit anti-CEBP $\beta$ antibodies (1:200; Santa Cruz Biotechnology, Santa Cruz, CA, USA) at $4{ }^{\circ} \mathrm{C}$ overnight in a humidified chamber, then incubated with HRP-conjugated goat anti-rabbit antibodies (1:500; Proteintech Group) at $37^{\circ} \mathrm{C}$ for $30 \mathrm{~min}$, and then detected with 3,3'-diaminobenzidine (DAB) (Dako, Glostrup, Denmark) and counterstained with Mayer's hematoxylin solution (Sigma-Aldrich). Seeing that there existed differences from IHC staining, rabbit anti-Ki67 (1:200; Invitrogen, Carlsbad, CA, USA) and mouse anti-CD133 (Proteintech Group, Chicago) and mouse anti-CD13 (Proteintech Group) antibodies were used for immunofluorescence (IF) staining. Nuclei were labeled with the blue fluorescent Hoechst 33342 dye.

\section{Colony-formation assays}

For colony-formation assays, 1,000 Huh7 cells or 2,000 CLC13 cells per well were plated on six-well plates and cultured for 7 days. Then, cells were fixed with $4 \%$ formaldehyde for $10 \mathrm{~min}$ and stained with crystal violet solution. The number of clones ( $>50$ cells) was counted microscopically.

\section{CCK8 assays}

For CCK8 assays, 1,200 Huh7 cells or 3,000 CLC13 cells per well were plated on 96-well plates and incubated for $24 \mathrm{~h}$. Then, $10 \mu \mathrm{L}$ CCK8 reagent was added to each well and incubated for $2 \mathrm{~h}$ at $37^{\circ} \mathrm{C}$. The optical density value was measured at a wavelength of $450 \mathrm{~nm}$ by using a microplate reader every day for 7 days.

\section{Flow cytometry and cell sorting}

Cells were dissociated into single cells by trypsinization and labeled with BV421-CD13 human antibody (301716, Biolegend, San Diego, CA, USA) at $4{ }^{\circ} \mathrm{C}$ for $15 \mathrm{~min}$. The concentration of the antibody used was according to the manufacturer's recommendation. The stained cells were analyzed or collected with the FACS Calibur machine (BD Biosciences).

\section{Cell cycle and cell apoptosis}

Cell cycle and cell apoptosis were assessed by the Cell Cycle Assay Kit (CCS012, MULTI Sciences) and the Annexin V-APC/7-AAD Apoptosis Detection Kit (AP105, MULTI Sciences), respectively, following the manufacturer's instructions.

\section{Sphere-formation assay}

Hepatoma cells were plated on six-well ultra-low attachment culture plates (Corning) in DMEM/F12 supplemented with $\mathrm{B} 27, \mathrm{~N} 2,20 \mathrm{ng} / \mathrm{mL}$ EGF and $20 \mathrm{ng} / \mathrm{mL}$ basic fibroblast growth factor (bFGF), and cultured in a $\mathrm{CO}_{2}$ incubator for 7 days. The number of spheroids was counted under a microscope.

For separation of oncospheres and nonsphere cells, we collected sphere-formation medium containing both nonsphere and sphere cells in a $15-\mathrm{mL}$ centrifuge tube. Pellets formed after 5-min tranquilization were recognized as spheres. The supernatant was then moved into a new centrifuge tube carefully and centrifuged at $1,500 \mathrm{~g}$ for $5 \mathrm{~min}$ to obtain nonspheric pellets.

\section{In vitro migration and invasion assays}

Cell migration was assessed by wound-healing and Transwell assays. For the wound-healing assay, a scratch was made in the center of the culture dish using a sterile $20-\mu \mathrm{L}$ pipette tip before cells were fully confluent. The wound was observed using a bright-field microscope at 24- and 48 -h after scratching. The migration rate $=($ scratch widths before migration - scratch widths after migration)/scratch widths before migration $\times 100 \%$. Transwell migration assay was conducted using 24-well Transwell Chambers without Matrigel (BD Biosciences) according to the manufacturer's instructions. Briefly, $1 \times 10^{5}$ Huh 7 cells or $1 \times 10^{5}$ CLC 13 cells in medium with $10 \%$ FBS were added to the top chamber, and the medium containing $20 \%$ FBS was added to the bottom chamber as an attractant. After 48-h incubation, the migrated cells were fixed and stained with crystal violet. The number of migrated cells was counted in 10 fields under a $10 \times$ objective lens. 
Transwell invasion assay was conducted using 24-well BioCoat Matrigel Invasion Chambers (BD Biosciences) according to the manufacturer's instructions. Briefly, $4 \times 10^{5}$ Huh7 cells in medium with $10 \%$ FBS were added to the top chamber, and the medium containing $20 \% \mathrm{FBS}$ was added to the bottom chamber as an attractant. The remaining steps are the same as those described for the Transwell migration assay.

\section{In vivo xenograft experiments}

For tumor growth assays, $5 \times 10^{5} \mathrm{Huh} 7$ cells or $1 \times 10^{6} \mathrm{CLC} 13$ cells were subcutaneously injected into 6 -week-old male $\mathrm{BALB} / \mathrm{c}$ nude mice. Every 3 days, tumor volume was calculated by the formula $\mathrm{V}=0.5 \mathrm{~W}^{2} \mathrm{~L}$ ( $\mathrm{V}$, volume; $\mathrm{L}$, length; and $\mathrm{W}$, width). BALB/c nude mice were obtained from the Animal Centre of the Chinese Academy of Medical Sciences, they were fed in standard pathogen-free conditions, and all animal experiments were in accordance with the Guide for the Care and Use of Laboratory Animals and were approved by the Institutional Animal Care and Use Committee of the Second Military Medical University.

\section{Statistical analysis}

All data are presented as the mean \pm SD. Statistical methods were indicated in figure legends, and statistical computations were conducted using GraphPad Prism version 6.0. $P<0.05$ was considered statistically significant; ${ }^{*}, * *$, and $* * *$ indicate $P<0.05, P<0.01$, and $P<0.001$, respectively.

\section{Results \\ LAPI is weakly expressed in HCC}

The result of an online-available HCC transcriptome dataset (GSE62232) analysis showed that CEBP $\beta$ was weakly expressed in HCC tumors (Figure 1A, Student's $t$-test, $* P<0.05)$. In addition, qRT-PCR showed that the expression level of LAP1 mRNA in HCC tissues was significantly lower than that in seven pairs of matched para-tumoral liver tissues (Figure 1B, Student's $t$-test, ${ }^{*} P<0.05$ ). These findings were further validated by IHC staining. At the same time, H\&E staining of the same tissue samples was done to confirm the pathological type of HCC (Figure 1C). The result showed that LAP1 was significantly downregulated in
A

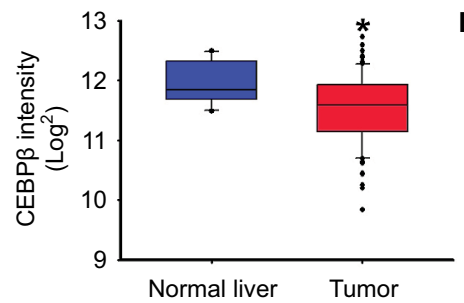

C

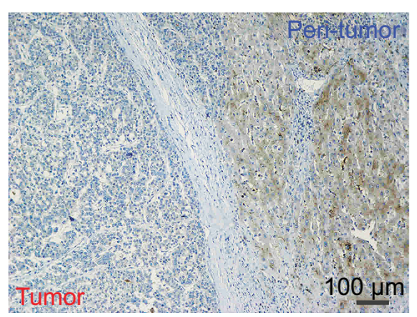

D

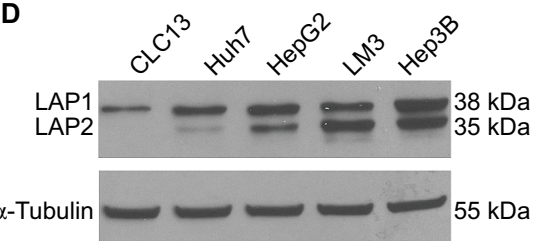

B
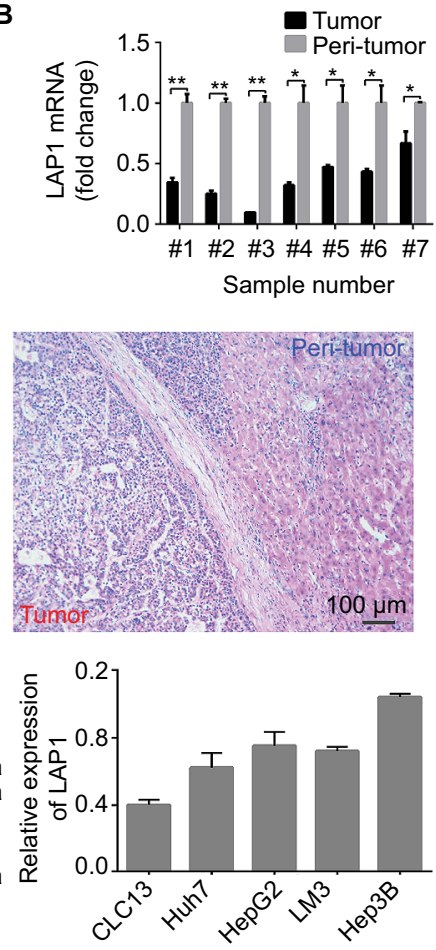

Figure I LAPI is weakly expressed in HCC.

Notes: (A) CEBP $\beta$ was weakly expressed in patients with HCC. CEBP $\beta$ expression in HCC tumor and normal liver tissues provided by Park's cohort (GSE62232) was analyzed. (B) LAPI expression levels were verified in samples of patients with HCC by qRT-PCR. GAPDH served as a loading control. (C) HCC samples were assayed by immunohistochemical and H\&E staining. Scale bar: $100 \mu \mathrm{m}$. (D) The endogenous levels of liver-enriched activating protein and liver-enriched inhibitory protein were determined by Western blot using rabbit IgG anti-CEBP $\beta$ (sc-150) and horseradish peroxidase-labeled anti-rabbit lgGs. The $\alpha$-tubulin protein level was used as a loading control (left panel). For each cell, three independent protein samples were analyzed, and each band was quantified and LAPI protein expression was normalized with the expression level of the $\alpha$-tubulin gene. Mean \pm SD are represented (right panel). Student's $t$-test was used for statistical analysis, $* P<0.05$ and $* * P<0.01$; data are shown as mean \pm SD. Data are representative of at least three independent experiments.

Abbreviations: CEBP $\beta$, CCAAT/enhancer binding protein beta; HCC, hepatocellular carcinoma; IgG, immunoglobulin G; LAPI, liver-enriched activator protein I; qRT$\mathrm{PCR}$, quantitative real time polymerase chain reaction. 
HCC tumor tissues as compared with para-tumoral tissues. Then, we measured the expression level of CEBP $\beta$ in five human hepatoma cell lines (Huh7, Hep3B, HepG2, LM3, and CLC13) and found that Huh7 and CLC13 cell lines contained the lowest amounts of LAP1 among these cell lines (Figure 1D) and, therefore, these two cell lines were used in our further experiments.

\section{LAPI is weakly expressed in LCSCs}

Knowing that CSCs play complex roles in the development and progression of cancer, we further investigated the expression of LAP1 in LCSCs. CD13 is known to be a target for identifying CSCs in a proportion of HCC; therefore, we sorted $\mathrm{CD} 13^{+}$cells from Huh7 and CLC13 HCC cell lines as LCSCs. Then, we tested the LAP1 expression in $\mathrm{CD} 13^{+}$ CSCs and $\mathrm{CD}^{-} 3^{-}$non-CSCs of the two cell lines and found that the LAP1 expression in $\mathrm{CD} 13^{+} \mathrm{CSC}$ s was significantly lower than that in $\mathrm{CD}^{-} 3^{-}$non-CSCs (Figure 2A). Furthermore, we conducted an oncosphere experiment, and the results showed that LAP1 expression in CSC-enriched spheres was significantly lower than that in nonspheres. Importantly, through serial passage of Huh7 and CLC13 sphere cells, similar observations were obtained in the following three generations of oncosphere assay (Figure 2B). Altogether, LAP1 was weakly expressed in HCC tumor tissues and LCSCs.
A

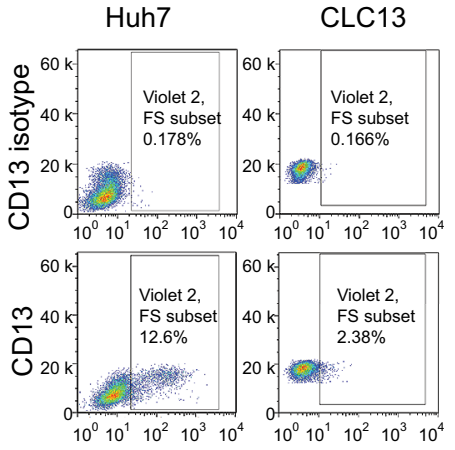

B
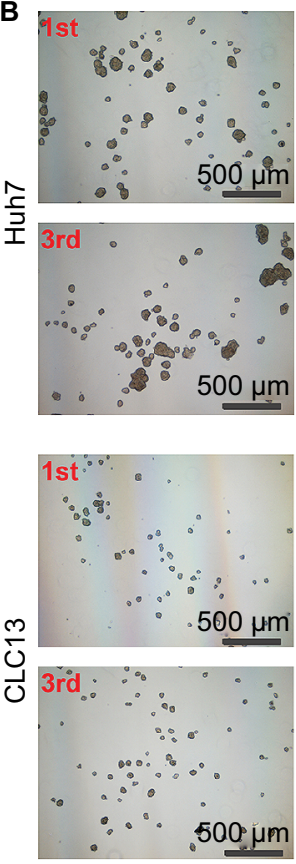
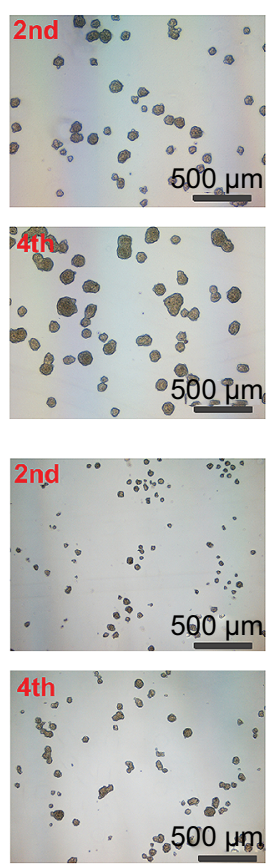

$\mathrm{CD} 13^{+} \mathrm{CSCs}$

CD13- Non-CSCs
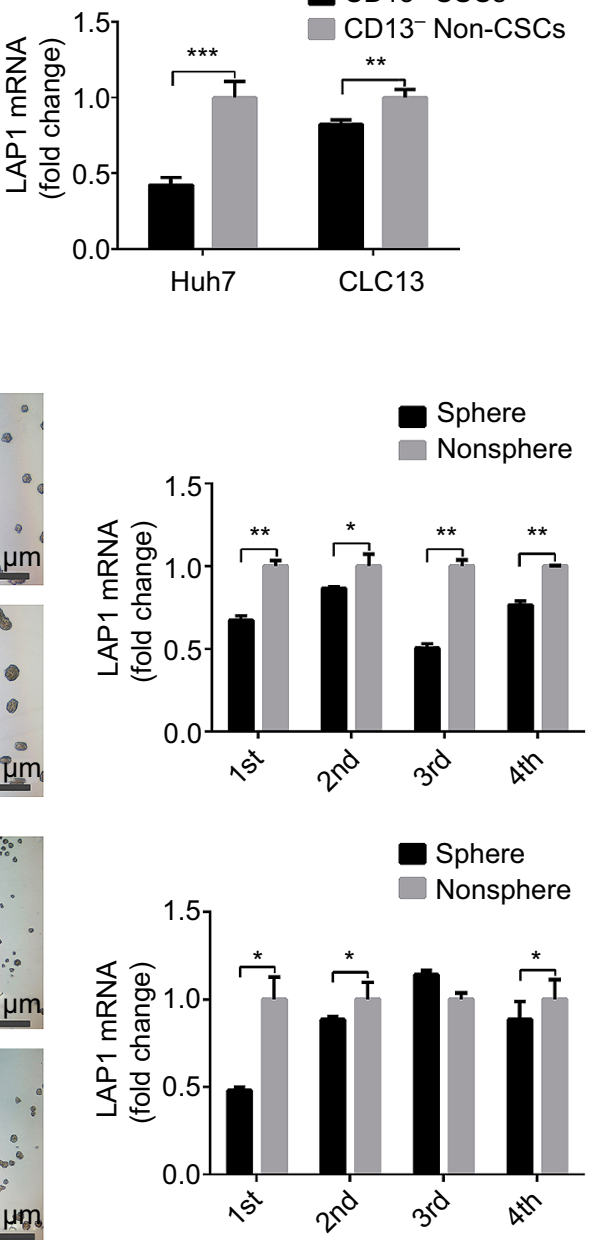

Figure 2 LAPI is weakly expressed in liver CSC.

Notes: (A) LAPI was weakly expressed in CDI $3^{+}$cells sorted from Huh7 and CLCI 3 cells. LAPI messenger RNA (mRNA) was measured by qRT-PCR. (B) LAPI was even more weakly expressed in oncospheres than in nonsphere tumor cells; through serial passage of Huh7 and CLCI 3 sphere cells, similar observations were obtained in the first, second, third, and fourth generations of oncosphere assay. Nonsphere: Huh7 or CLCl 3 cells that failed to form spheres. Scale bar: $500 \mu m$. Student's $t$-test was used for statistical analysis, $* P<0.05$, $* * P<0.01$, $* * * P<0.001$; data are shown as mean $\pm S D$. Data are representative of at least three independent experiments.

Abbreviations: CSC, cancer stem cells; LAPI, liver-enriched activator protein I; qRT-PCR, quantitative real time polymerase chain reaction. 


\section{LAPI inhibits the stemness of LCSCs}

To explore the function of LAP1 in HCC, we constructed Huh7 and CLC13 cells stably expressing LAP1 by using the lentivirus infection system, and an pLVX-AcGFP1-N1 (AcGFP)-overexpressing empty vector was used as the control (Figure 3A). Notably, flow cytometric analysis revealed that LAP1 overexpression decreased the number of $\mathrm{CD} 13^{+}$ liver CSCs markedly (Figure 3B). Compared with the control, the mRNA level of CSC markers CD133, CD13, and EpCAM was significant downregulated in both Huh7 and CLC13 cells infected with LAP1 (Figure 3C). Furthermore, sphere-formation experiments showed that LAP1 overexpression dramatically decreased oncosphere formation as compared with the AcGFP-overexpressing group (Figure 3D). These data indicate that LAP1 overexpression suppressed the stemness features of LCSCs.

\section{LAPI suppresses the proliferation of $\mathrm{HCC}$ cell lines in vitro}

Seeing that LAP1 inhibited the stemness features of LCSCs, we explored whether LAP1 played a critical role in the expansion of HCC cell lines. We conducted CCK8 cell-proliferation and colony-formation assays to explore the effect of LAP1 expression on the proliferation of HCC cells. Compared with the control, LAP1 overexpression suppressed the proliferation of Huh7 and CLC13 cells markedly (Figure 4A). The colony-formation assay showed that LAP1 overexpression could also markedly reduce the frequency of colony formation in Huh7 and CLC13 cells (Figure 4B and C).

To distinguish between the possibilities that LAP1 overexpression inhibited growth or caused cell death in hepatoma cells, we undertook flow cytometry to quantitate the population of apoptotic cells and cell cycle distribution. Compared with AcGFP overexpression, LAP1 overexpression promoted G1/G0 phase arrest in Huh7 and CLC13 cells (Figure 4D), whereas no cell apoptosis was observed in these two cell lines (Figure S1).

\section{LAPI inhibits the migration and invasion of $\mathrm{HCC}$}

To explore the function of LAP1 on the migration and invasion of HCC cells, wound-healing and Transwell migration assays were conducted. It was found that LAP1 suppressed the migratory ability of Huh7 and CLC13 cells efficiently (Figure 5A-D). The result of a Matrigel invasion assay showed that LAP1 suppressed the invasive ability of Huh7 cells (Figure 5E). These findings demonstrate that LAP1 possesses antitumor activity in $\mathrm{HCC}$ cells.

\section{LAPI suppressed the tumor proliferation and stemness of HCC in vivo}

For the in vivo tumor-formation assay, tumor formation was observed in nude mice injected with LAP1-transfected and AcGFP empty vector-transfected Huh7 and CLC13 cells. In addition, the tumor size and tumor volume in the LAP1 overexpression group were significantly smaller than those in the AcGFP empty vector-transfected cell group. The tumor size was measured every 3 days and, after 1 month, the mice were sacrificed, and the tumors were removed and weighed (Figure 6A). Then, the tumors were paraffin embedded and IF stained. Using a rabbit CEBP $\beta$ antibody, the overexpression of LAP1 was confirmed (Figure 6B). Furthermore, the result showed that the intensity of CD13, CD133, and Ki67 was obviously lower in LAP1-overexpressing CLC13 cells than in the control, indicating that LAP1 overexpression was negatively correlated with the LCSC markers CD13 and CD133 as well as Ki67 (Figure 6C-E). Taken together, LAP1 overexpression inhibited xenograft tumor growth and stemness markedly, suggesting that LAP1 plays a tumor suppressor role in HCC.

\section{Discussion}

Several studies have highlighted the crucial role of CEBP $\beta$ in suppressing tumor features. For example, forced expression of CEBP $\beta$ in HepG2 hepatocarcinoma cells induced arrest of cells at or near the G1-S boundary. ${ }^{28} \mathrm{CEBP} \beta$ knockout mice developed a lymphoproliferative disorder, suggesting that CEBP $\beta$ inhibited the expansion of the lymphoid cell compartment. ${ }^{29}$ CEBP $\beta$ was found to be expressed at a low level in hematological malignancies in chronic myelogenous leukemia. CEBP $\beta$ played a role in the $\mathrm{BCR} / \mathrm{ABL}$ of bone marrow progenitor cells by activating the transcription and expression of the downstream target gene GADD45A, thus promoting cell differentiation and inhibiting cell proliferation. ${ }^{30}$

However, growth arrest induced by CEBP $\beta$ is highly context specific because $C E B P \beta$ was found to display growthpromoting activity in several cases. CEBP $\beta$ can function as a pro-oncogenic transcription factor that promotes proliferation and/or survival of some tumor cells. For example, deletion of the $C E B P \beta$ gene rendered mice totally resistant to carcinogen-induced skin tumor development. ${ }^{31}$ Shimizu et a $l^{32}$ reported that CEBP $\beta$ inhibited apoptosis and improved the survival rate of pancreatic cancer cells. Gardiner et $\mathrm{al}^{33}$ found that $\mathrm{CEBP} \beta-1$ overexpression increased transformation and upregulated the expression of the CSC marker ALDH1A1, leading to chemoresistance in Ewing sarcoma. Therefore, CEBP $\beta$ can function as a pro-oncogenic transcription factor 
A

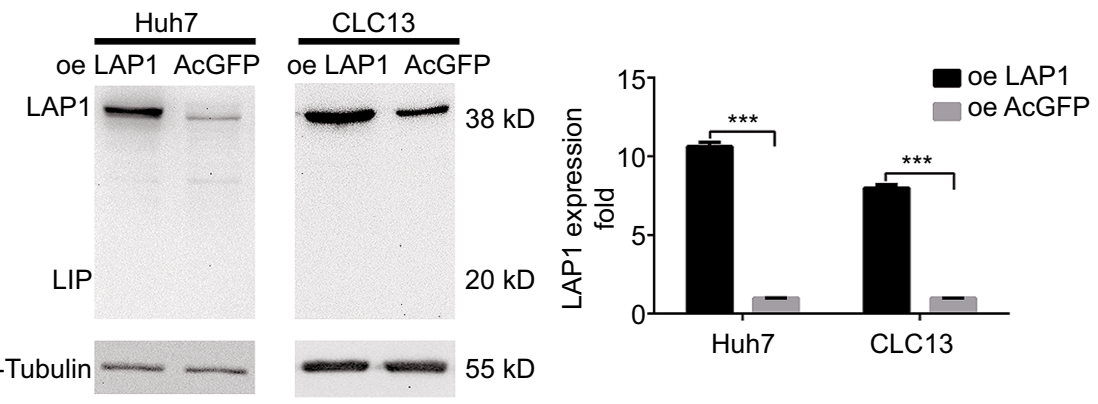

B
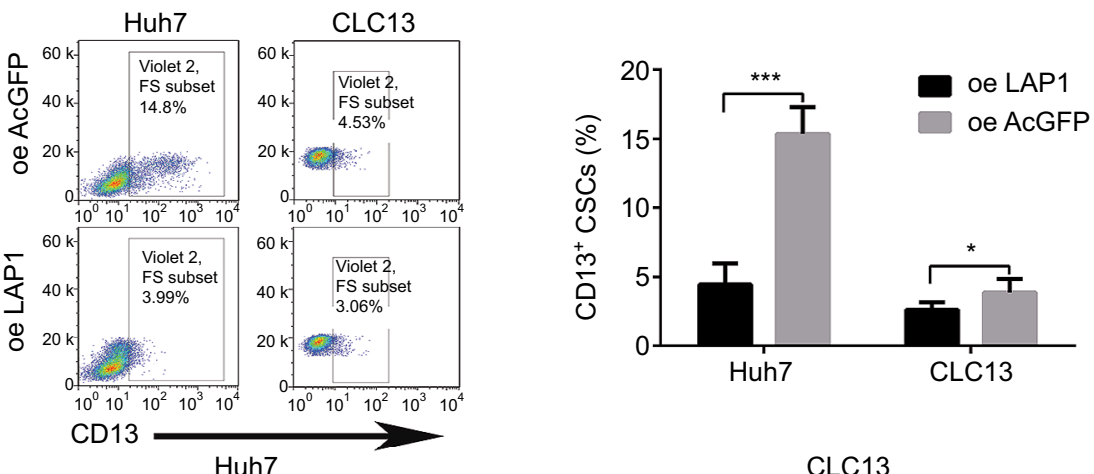

C

Huh7
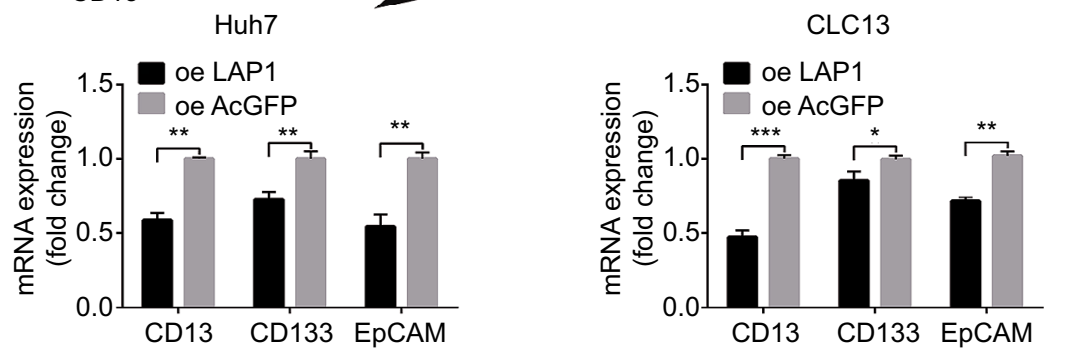

D

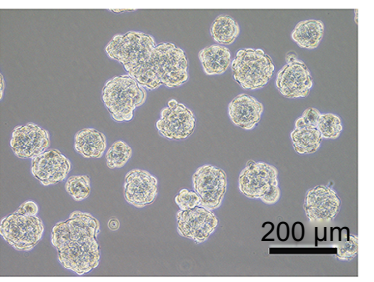

oe LAP1

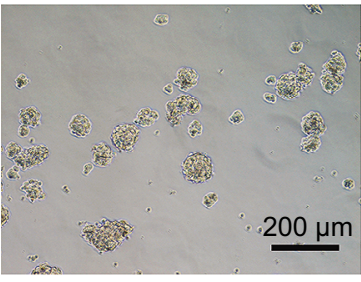

oe LAP1
Huh7

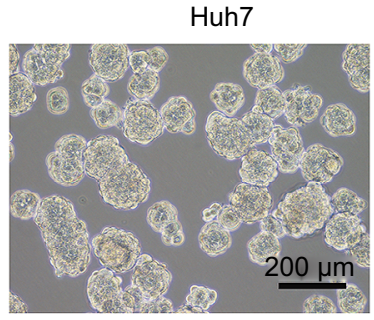

oe AcGFP

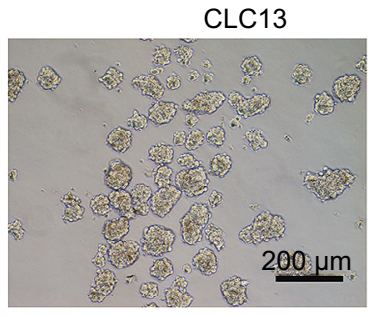

oe AcGFP

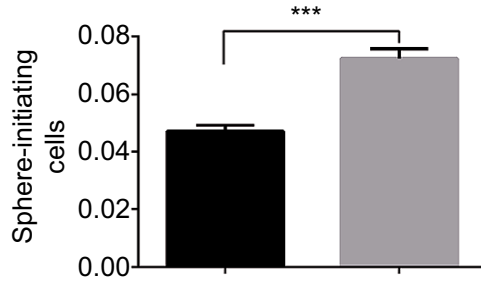

oe LAP1 oe AcGFP

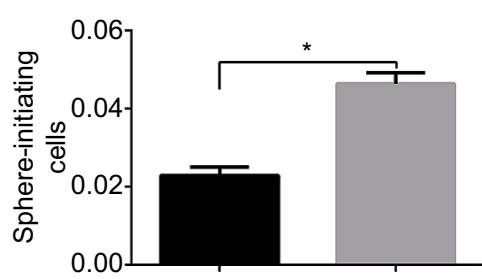

oe LAP1 oe AcGFP

Figure 3 LAPI inhibits the stemness of liver CSCs.

Notes: (A) LAPI-overexpressing Huh7 cells and control Huh7 cells were established. LAPI-overexpressing CLCI3 cells and control CLCI 3 cells were established (left panel). For each cell, three independent RNA samples were analyzed and CEBP $\beta$ mRNA expression was normalized with the expression level of the GAPDH gene. Mean \pm SD are represented (right panel). (B) CDI3+ (CSC) subpopulations were detected in LAPI-overexpressing Huh7 and LAPI-overexpressing CLCI 3 cells and their control cells by fluorescence-activated cell sorting (FACS) analysis. Results are shown as mean \pm SD. (C) Expression of CDI3, CDI33, and EpCAM (stemness-associated transcription factors) in LAPI-overexpressing Huh7 and LAPI-overexpressing CLCI3 cells, and their control cells were compared by real-time PCR. Significant downregulation in CDI3, CDI33, and EPCAM mRNA levels was detected in both cell lines after overexpressing LAPI. Results are shown as mean \pm SD. (D) LAPI overexpression causes a diminished oncosphere-forming capacity in Huh7 and $\mathrm{CLCl} 3$ cells. The right panel represents statistical results as mean \pm SD. Scale bar, $200 \mu \mathrm{m}$. $* P<0.05$, $* * P<0.0 \mathrm{I}, * * * P<0.00 \mathrm{I}$.

Abbreviations: CEBP $\beta$, CCAAT/enhancer binding protein beta; CSC, cancer stem cell; EPCAM, epithelial cell adhesion molecule; LAPI, liver-enriched activator protein I; oe, overexpression; PCR, polymerase chain reaction. 
A

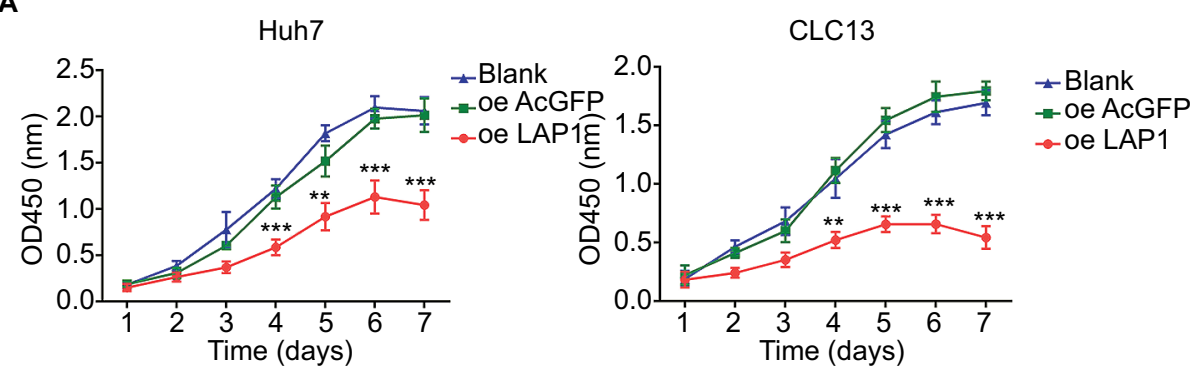

B

Huh7

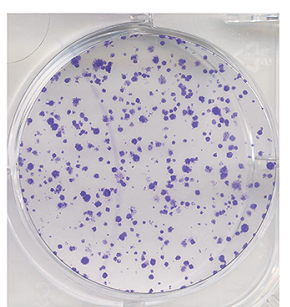

oe LAP1

C

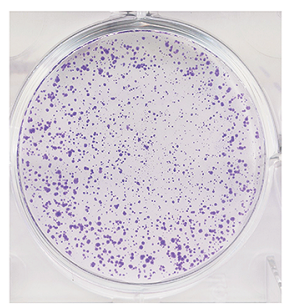

oe LAP1

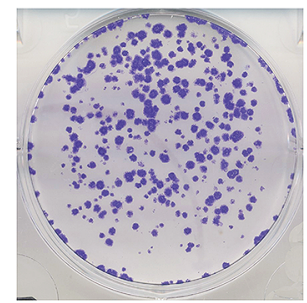

oe AcGFP

CLC13

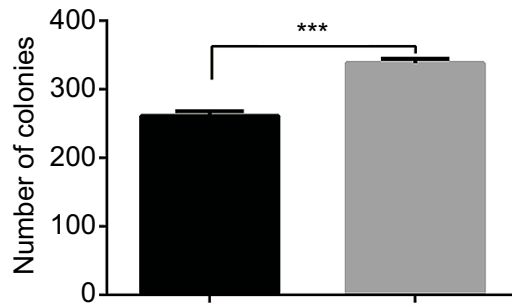

oe LAP1

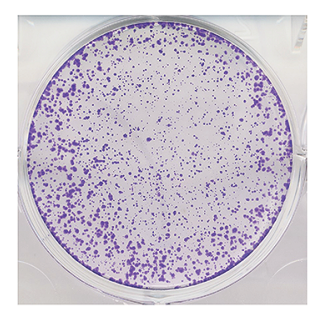

oe AcGFP

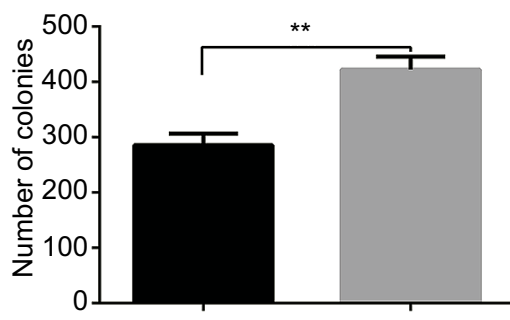

oe LAP1

D

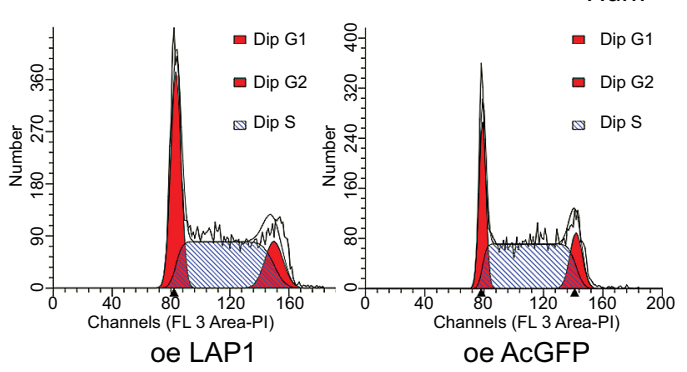

CLC13
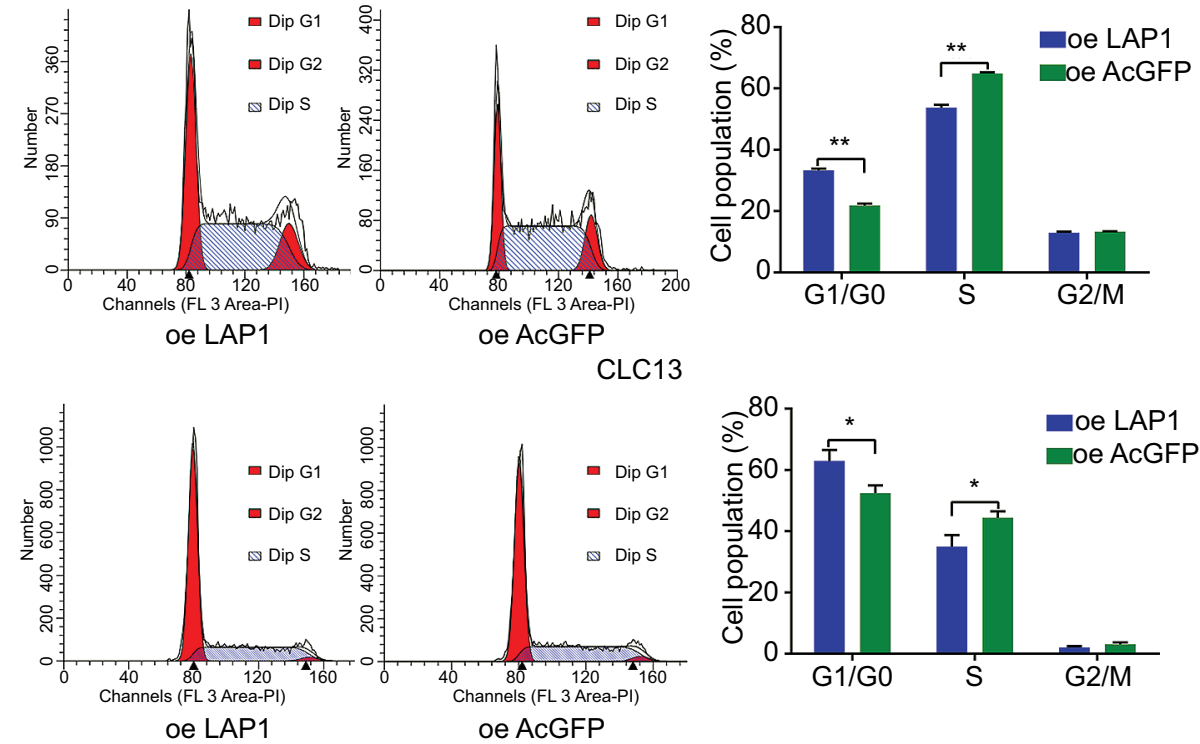

Figure 4 LAPI suppress the proliferation of HCC cell line in vitro.

Notes: (A) The suppression rate was up to more than $50 \%$ on the sixth day after LAPI infection, compared with AcGFP and noninfected control groups (one-way analysis of variance). ${ }^{*} P<0.05,{ }^{*} P<0.0 \mathrm{I}$, and $* * * P<0.00 \mathrm{I}$. (B and $\left.\mathbf{C}\right)$ Both $\mathrm{HCC}$ cell lines infected with LAPI formed fewer and smaller colonies than those infected with AcGFP. Each value represents the mean \pm SD for triplicate samples (Student's $t$-test). ${ }^{*} P<0.05, * * P<0.0 \mathrm{I}$, and $* * * P<0.00 \mathrm{I}$. (D) The cell cycle transition of Huh7 and CLCI 3 cells was examined, and the increase of the percentage of cells in GI/G0 phase was caused in both cell lines by LAPI overexpression. All experiments were repeated at least three times, and representative data are shown. Each value represents the mean \pm SD for triplicate samples (Student's $t$-test). $* P<0.05$, $* * P<0.0 \mathrm{I}$, and $* * * P<0.00 \mathrm{I}$.

Abbreviations: HCC, hepatocellular carcinoma; LAPI, liver-enriched activator protein I; oe, overexpression. 
A

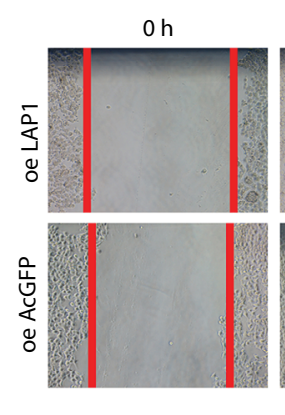

B

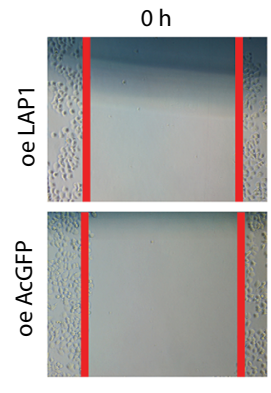

C

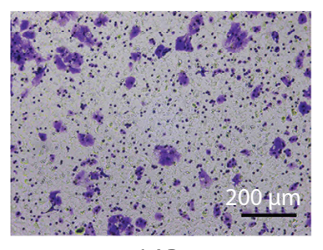

oe LAP1

D

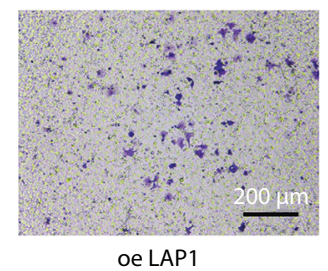

E
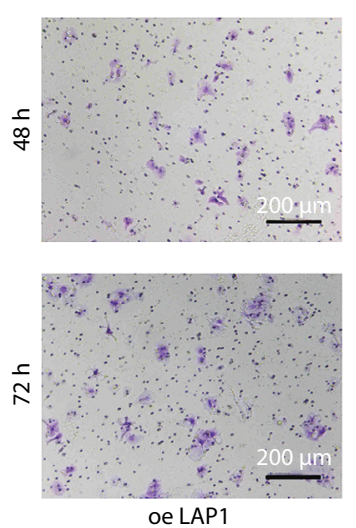

$24 \mathrm{~h}$

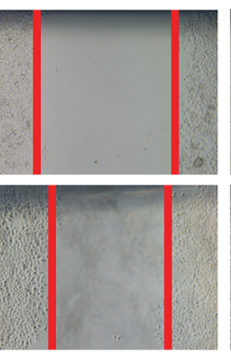

$24 \mathrm{~h}$

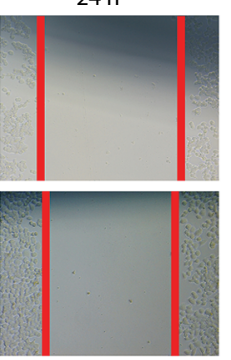

Huh7
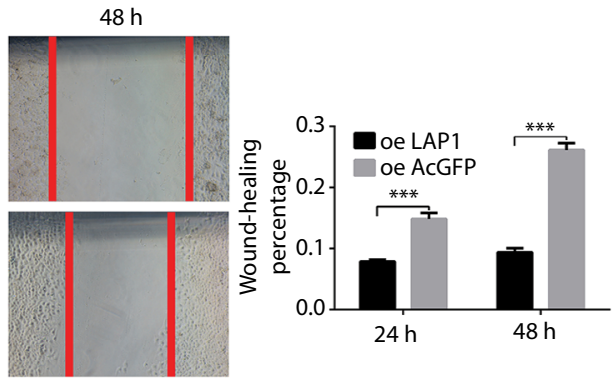

CLC13
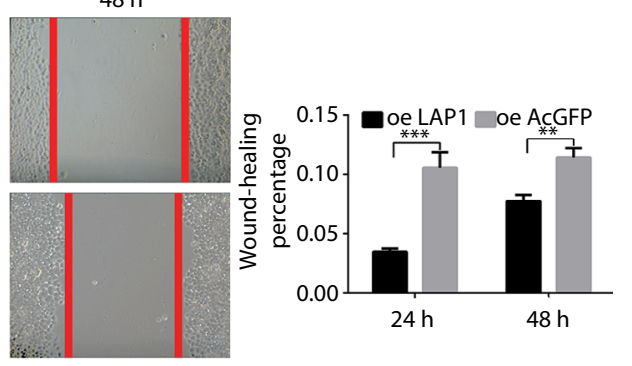

Huh7
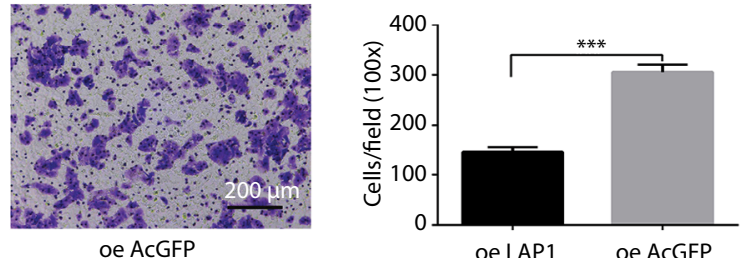

$\mathrm{CLC13}$
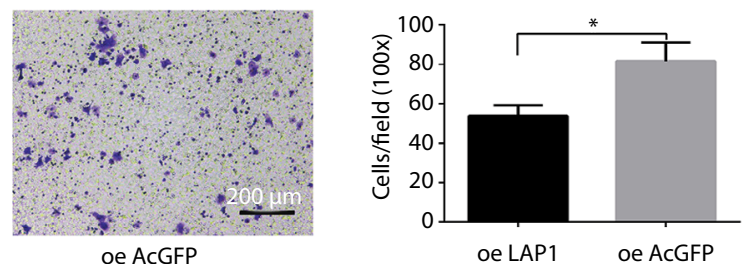

Huh7
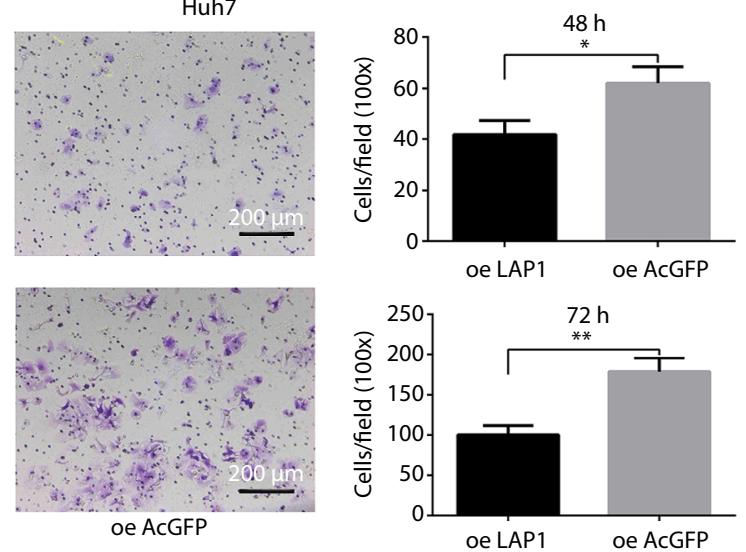

Figure 5 LAPI inhibits the migration and invasion of HCC.

Notes: (A and B) A wound-healing assay showed that cell motility was suppressed by LAPI overexpression in Huh7 and CLCI 3 cells. Microscopic images were acquired at

0,24 , and $48 \mathrm{~h}$ after scratching the surface of a confluent layer of cells. (C and D) The in vitro migration ability of Huh7 and CLCI3 cells infected with LAPI was assessed using Transwell assays. Cells infected with AcGFP were used as a control. Scale bar, $200 \mu \mathrm{m}$. (E) Matrigel invasion assay was conducted to compare the cell invasion ability between LAPI-overexpressing and control Huh7 cells after 48- and 72-h infection. Invaded cells were fixed and stained with crystal violet, Scale bar, $200 \mu \mathrm{m}$. The number of invaded cells was calculated and is shown in the bar chart. All data are mean \pm SD of three independent experiments $\left({ }^{*} P<0.05\right.$, ${ }^{* * P}<0.01, * * * P<0.001$, Student's $t$-test). Abbreviations: LAPI, liver-enriched activator protein; oe, overexpression. 
A

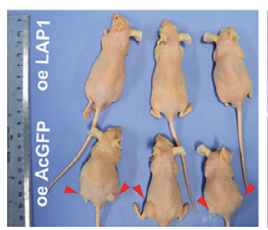

B

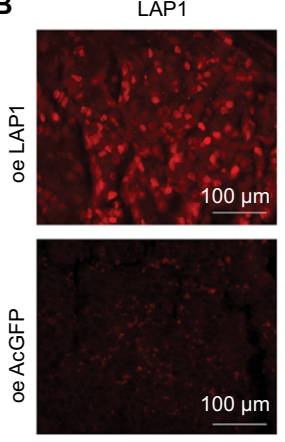

D
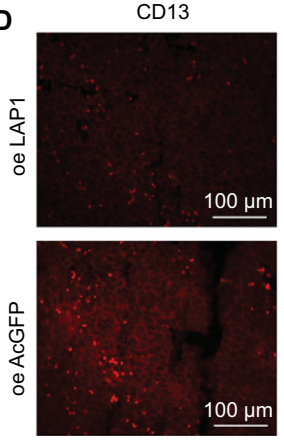

Huh7

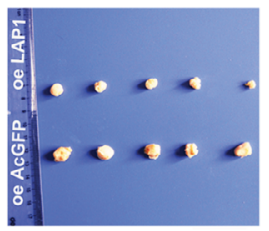

Hoechst 33342

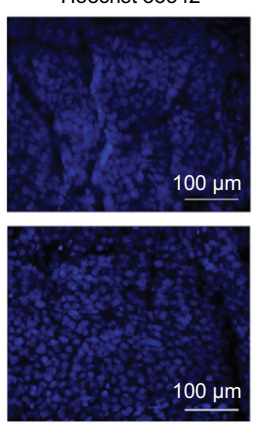

Hoechst 33342
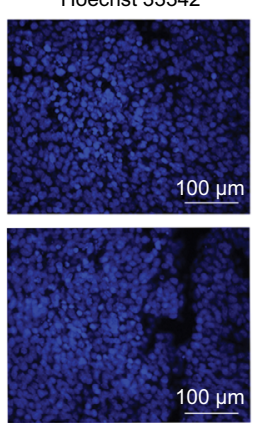

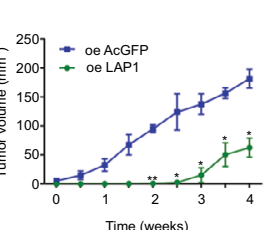

Merge

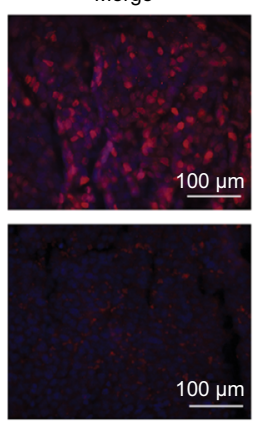

Merge
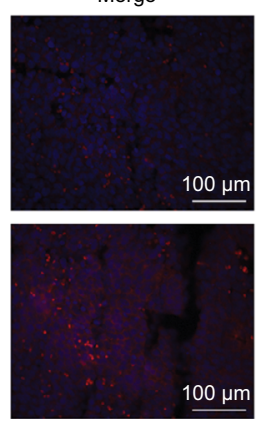
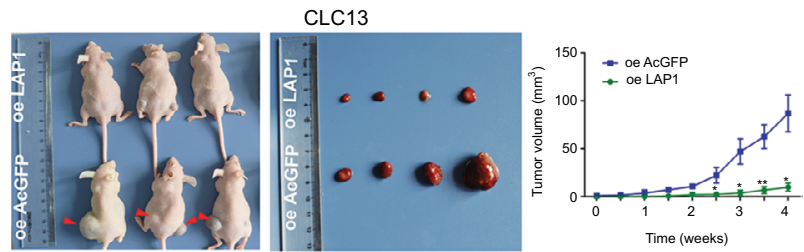

C

CD133
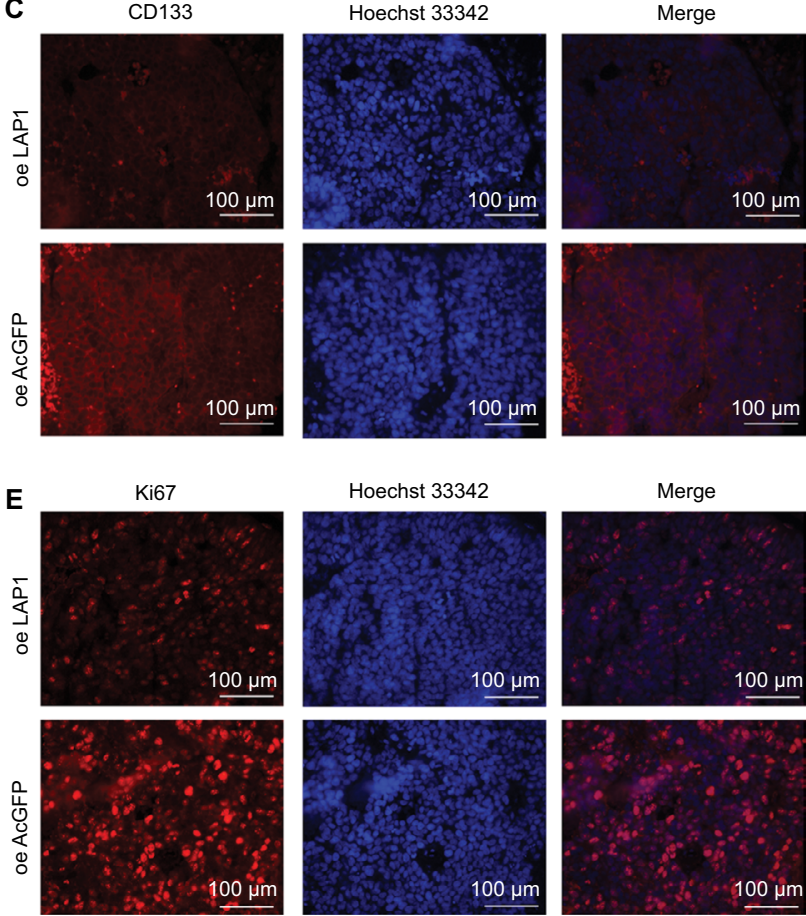

Figure 6 LAPI suppresses the tumor proliferation and stemness of HCC in vivo.

Notes: (A) LAPI-overexpressing and AcGFP-overexpressing Huh7 cells $\left(5 \times 10^{5}\right)$ and LAPI-overexpressing and AcGFP-overexpressing CLCI3 cells (I $\left.\times 10^{6}\right)$ were subcutaneously injected into BALB/c nude mice for observation of tumor growth. Tumor sizes were observed every 3 days and photographed weekly, and representative pictures are shown. After a 4-week tumor observation, the animals were sacrificed and tumors were removed and weighed. Growth curves of tumors over 4 weeks are summarized and analyzed. Results are shown as mean $\pm S D, n=6$ for each group. (B) The xenograft from the nude mice originated from CLCI 3 cells were paraffin embedded and IF stained. The level of CEBP $\beta$ was monitored using a rabbit CEBP $\beta$ antibody, and the overexpression of LAPI was confirmed. Scale bars: I00 $\mu$ m. (C-E) The level of $\mathrm{CDI} 3$ or $\mathrm{CDI} 33$ or Ki67 was compared and analyzed with corresponding antibodies and then counterstained with Hoechst 33342 for confocal microscopy. The images are representative of the results obtained. Scale bars, $100 \mu \mathrm{m}$.

Abbreviations: CEBP $\beta$, CCAAT/enhancer binding protein beta; HCC, hepatocellular carcinoma; IF, immunofluorescence; LAPI, liver-enriched activator protein I; oe, overexpression.

that promotes proliferation and survival of some tumor cells. How it stimulates mitotic growth and why it elicits a completely opposite effect on proliferation in different cellular contexts are intriguing questions for future investigation.

The incidence and mortality of HCC are at the forefront of all malignancies. ${ }^{1,3}$ Although great progress has been made in the diagnosis and treatment of liver cancer, tumor recurrence and metastasis in patients with liver cancer remain the main reasons for poor prognosis. ${ }^{4} \mathrm{CSC}$ s have some characteristics including self-renewal, differentiation, and the ability to form a new tumor. ${ }^{34}$ Studies have confirmed that CSCs may be responsible for cancer development, relapse, and metastasis. Human HCC is driven and maintained by LCSCs. Thus, targeting CSCs may become a promising therapeutic strategy to cure deadly malignancies.
Furthermore, CEBP $\beta$ expression has been linked to a variety of rodent and human cancers. ${ }^{20} \mathrm{CEBP} \beta$ appears to play a critical role in the development of both the mammary gland and cancers through its involvement in the development, differentiation, and proliferation of mammary epithelial cells. ${ }^{35-37}$

LAP1 is the most highly expressed isoform of CEBP $\beta$, which is a liver-enriched transcription factor involved in cellular metabolism, development, proliferation, and differentiation. In this study, our observations were confirmed by Park's cohort dataset GSE62232. We found that LAP1 was weakly expressed in $\mathrm{HCC}$ tumors and LCSCs, indicating that LAP1 may play a negative regulatory role in CSCs. However, no study has explored the function of LAP1 in LCSCs and other kinds of CSCs. 
The self-renewal capacity of CSCs is known to be one of the important features for the development of cancer. To explore the function of LAP1 on the self-renewal capacity of LCSCs, we first measured the effect of LAP1 on the proliferative capacity of HCC cell lines. The results showed that LAP1 overexpression was able to inhibit the proliferative capacity of HCC cells, and that LAP1 could attenuate the stemness of HCC. Moreover, stem cell-associated membrane markers can be used to measure the stemness of HCC cells. Knowing that CD133, CD13, and EpCAM are the most useful stemness biomarkers, we conducted qRT-PCR and IF to measure their expressions, and found that LAP1 could decrease the expression of CD133, CD13, and EpCAM, thus suggesting that LAP1 could attenuate the stemness of HCC and inhibit the self-renewal ability of LCSCs. Furthermore, the sphere-formation experiment was conducted, knowing that it is an important experiment to measure the self-renewal capacity of HCC. We found that LAP1 overexpression could inhibit the sphere formation of HCC in terms of the size and number of the spheres. According to the theory of CSCs, the subcutaneous tumor-formation ability is an important method to measure the self-renewal capacity of CSCs in mice. To explore the influence of LAP1 on the stemness of LCSCs, we transplanted HCC to the mice and built a subcutaneous tumor mice model. After approximately 1 month, differences between the LAP1 overexpression and control groups were observed. It was found that LAP1 could significantly inhibit the formation and growth of subcutaneous tumors; furthermore, when the tumors were paraffin embedded and IF stained, we found the intensities of CD13, CD133, and Ki67 were obviously lower in LAP1 overexpressing CLC13 cells than in the control, which strongly supports the conclusion that LAP1 can attenuate the stemness of LCSCs and HCCs. At the same time, we measured other tumor biological functions of LAP1 by the Transwell assay and scratch test, and found that LAP1 overexpression could inhibit the migration and invasion of HCC in vitro. Furthermore, LAP1 overexpression could cause cell cycle arrest in the G1/G0 phase, which also indicates the tumor suppressor gene function of this LAP1.

The above results demonstrated that LAP1 could suppress the self-renewal capability of LCSCs and may prove to be a target for eradicating LCSCs and a novel promising therapeutic approach for inhibiting liver cancer.

\section{Conclusion}

LAP1 was weakly expressed in HCC and LCSCs. LAP1 could suppress the self-renewal capability of LCSCs and possessed a tumor-suppressive effect on HCC cells, suggesting that LAP1 may serve as an optimal target in liver CSC-targeted therapy.

\section{Acknowledgments}

This study was supported by the National Natural Science Foundation of China (grant numbers 31771511 and 31401166), Shanghai Committee of Science and Technology of China (grant number 15JC1403900), and China Postdoctoral Science Foundation (grant number 2013M542434).

\section{Author contributions}

All authors contributed to the conception and design of the study, acquisition of data, or analysis and interpretation of the data, and to the critical revision of the manuscript for important intellectual content, gave final approval of the version to be published, and agree to be accountable for all aspects of the work.

\section{Disclosure}

The authors report no conflicts of interest in this work.

\section{References}

1. Torre LA, Bray F, Siegel RL, Ferlay J, Lortet-Tieulent J, Jemal A. Global cancer statistics, 2012. CA Cancer J Clin. 2015;65(2):87-108.

2. Wang R, Sun Q, Wang $P$, et al. Notch and Wnt/ $\beta$-catenin signaling pathway play important roles in activating liver cancer stem cells. Oncotarget. 2016;7(5):5754-5768.

3. Siegel RL, Miller KD, Jemal A. Cancer statistics, 2016. CA Cancer J Clin. 2016;66(1):7-30.

4. Maluccio M, Covey A. Recent progress in understanding, diagnosing, and treating hepatocellular carcinoma. CA Cancer J Clin. 2012;62(6):394-399.

5. Hao J, Zhang Y, Deng M, et al. MicroRNA control of epithelial-mesenchymal transition in cancer stem cells. Int $J$ Cancer. 2014;135(5):1019-1027.

6. Chiba T, Iwama A, Yokosuka O. Cancer stem cells in hepatocellular carcinoma: therapeutic implications based on stem cell biology. Hepatol Res. 2016;46(1):50-57.

7. Charafe-Jauffret E, Ginestier C, Iovino F, et al. Breast cancer cell lines contain functional cancer stem cells with metastatic capacity and a distinct molecular signature. Cancer Res. 2009;69(4):1302-1313.

8. Mackillop WJ, Ciampi A, Till JE, Buick RN. A stem cell model of human tumor growth: implications for tumor cell clonogenic assays. $J$ Natl Cancer Inst. 1983;70(1):9-16.

9. Bonnet D, Dick JE. Human acute myeloid leukemia is organized as a hierarchy that originates from a primitive hematopoietic cell. Nat Med. 1997;3:730-737.

10. MacDonagh L, Gray SG, Breen E, et al. Lung cancer stem cells: the root of resistance. Cancer Lett. 2016;372(2):147-156.

11. Tang DG, Patra Wala L, Calhoun T, et al. Prostate cancer stem/progenitor cells: identification, characterization, and implications. Moll Carcinogen. 2007;46(1):1-14.

12. Lathia JD, Mack SC, Mulkearns-Hubert EE, Valentim CL, Rich JN. Cancer stem cells in glioblastoma. Genes Dev. 2015;29(12):1203-1217.

13. Lee CJ, Dosch J, Simeone DM. Pancreatic cancer stem cells. J Clin Oncol. 2008;26(17):2806-2812. 
14. Tong CM, Ma S, Guan XY. Biology of hepatic cancer stem cells. $J$ Gastroenterol Hepatol. 2011;26(8):1229-1237.

15. Ji J, Wang XW. Clinical implications of cancer stem cell biology in hepatocellular carcinoma. Semin Oncol. 2012;39(4):461-472.

16. Yamashita T, Wang XW. Cancer stem cells in the development of liver cancer. J Clin Invest. 2013;123(5):1911-1918.

17. Yang Q, Wang Y, Yang Q, et al. Cuprous oxide nanoparticles trigger ER stress-induced apoptosis by regulating copper trafficking and overcoming resistance to sunitinib therapy in renal cancer. Biomaterials. 2017;146:72-85.

18. Yu B, Wang Y, Yu X, et al. Cuprous oxide nanoparticle-inhibited melanoma progress by targeting melanoma stem cells. Int J Nanomedicine. 2017;12:2553-2567.

19. Descombes P, Schibler U. A liver-enriched transcriptional activator protein, LAP, and a transcriptional inhibitory protein, LIP, are translated from the same mRNA. Cell. 1991;67(3):569-579.

20. Sebastian T, Johnson PF. Stop and go: anti-proliferative and mitogenic functions of the transcription factor C/EBPbeta. Cell Cycle. 2006;5(9):953-957.

21. Ramji DP, Foka P. CCAAT/enhancer-binding proteins: structure, function and regulation. Biochem J. 2002;365(Pt 3):561-575.

22. Saint-Auret G, Danan JL, Hiron M, et al. Characterization of the transcriptional signature of C/EBPbeta isoforms (LAP/LIP) in Hep3B cells: implication of LIP in pro-survival functions. J Hepatol. 2011;54(6):1185-1194.

23. Li W, Kessler P, Yeger H, et al. A gene expression signature for relapse of primary wilms tumors. Cancer Res. 2005;65(7):2592-2601.

24. Oya M, Horiguchi A, Mizuno R, Marumo K, Murai M. Increased activation of CCAAT/enhancer binding protein-beta correlates with the invasiveness of renal cell carcinoma. Clin Cancer Res. 2003;9(3):1021-1027.

25. Homma J, Yamanaka R, Yajima N, et al. Increased expression of CCAAT/ enhancer binding protein beta correlates with prognosis in glioma patients. Oncol Rep. 2006;15(3):595-601.

26. Fang T, Cui M, Sun J, et al. Orosomucoid 2 inhibits tumor metastasis and is upregulated by CCAAT/enhancer binding protein $\beta$ in hepatocellular carcinomas. Oncotarget. 2015;6(18):16106-16119.
27. Qiu Z, Zou K, Zhuang L, et al. Hepatocellular carcinoma cell lines retain the genomic and transcriptomic landscapes of primary human cancers. Sci Rep. 2016;6:27411.

28. Buck M, Turler H, Chojkier M. LAP (NF-IL-6), a tissue-specific transcriptional activator, is an inhibitor of hepatoma cell proliferation. EMBO J. 1994;13(4):851-860.

29. Screpanti I, Romani L, Musiani P, et al. Lymphoproliferative disorder and imbalanced T-helper response in C/EBP beta-deficient mice. $E M B O$ J. 1995;14(9):1932-1941.

30. Guerzoni C, Bardini M, Mariani SA, et al. Inducible activation of $\mathrm{CEBPB}$, a gene negatively regulated by $\mathrm{BCR} / \mathrm{ABL}$, inhibits proliferation and promotes differentiation of BCR/ABL-expressing cells. Blood. 2006;107(10):4080-4089.

31. Zhu S, Yoon K, Sterneck E, Johnson PF, Smart RC. CCAAT/enhancer binding protein-beta is a mediator of keratinocyte survival and skin tumorigenesis involving oncogenic Ras signaling. Proc Natl Acad Sci US A. 2002;99(1):207-212.

32. Shimizu Y, Kishimoto T, Ohtsuka M, et al. CCAAT/enhancer binding protein-beta promotes the survival of intravascular rat pancreatic tumor cells via antiapoptotic effects. Cancer Sci. 2007;98(11): 1706-1713.

33. Gardiner JD, Abegglen LM, Huang X, et al. C/EBP $\beta-1$ promotes transformation and chemoresistance in Ewing sarcoma cells. Oncotarget. 2017;8(16):26013-26026

34. Reya T, Morrison SJ, Clarke MF, Weissman IL. Stem cells, cancer, and cancer stem cells. Nature. 2001;414(6859):105-111.

35. Zahnow CA. CCAAT/enhancer binding proteins in normal mammary development and breast cancer. Breast Cancer Res. 2002;4(3): $113-121$.

36. Grimm SL, Rosen JM. The role of C/EBPbeta in mammary gland development and breast cancer. J Mammary Gland Biol Neoplasia. 2003;8(2):191-204.

37. Zahnow CA. CCAAT/enhancer-binding protein beta: its role in breast cancer and associations with receptor tyrosine kinases. Expert Rev Mol Med. 2009;11:e12. 


\section{Supplementary materials}

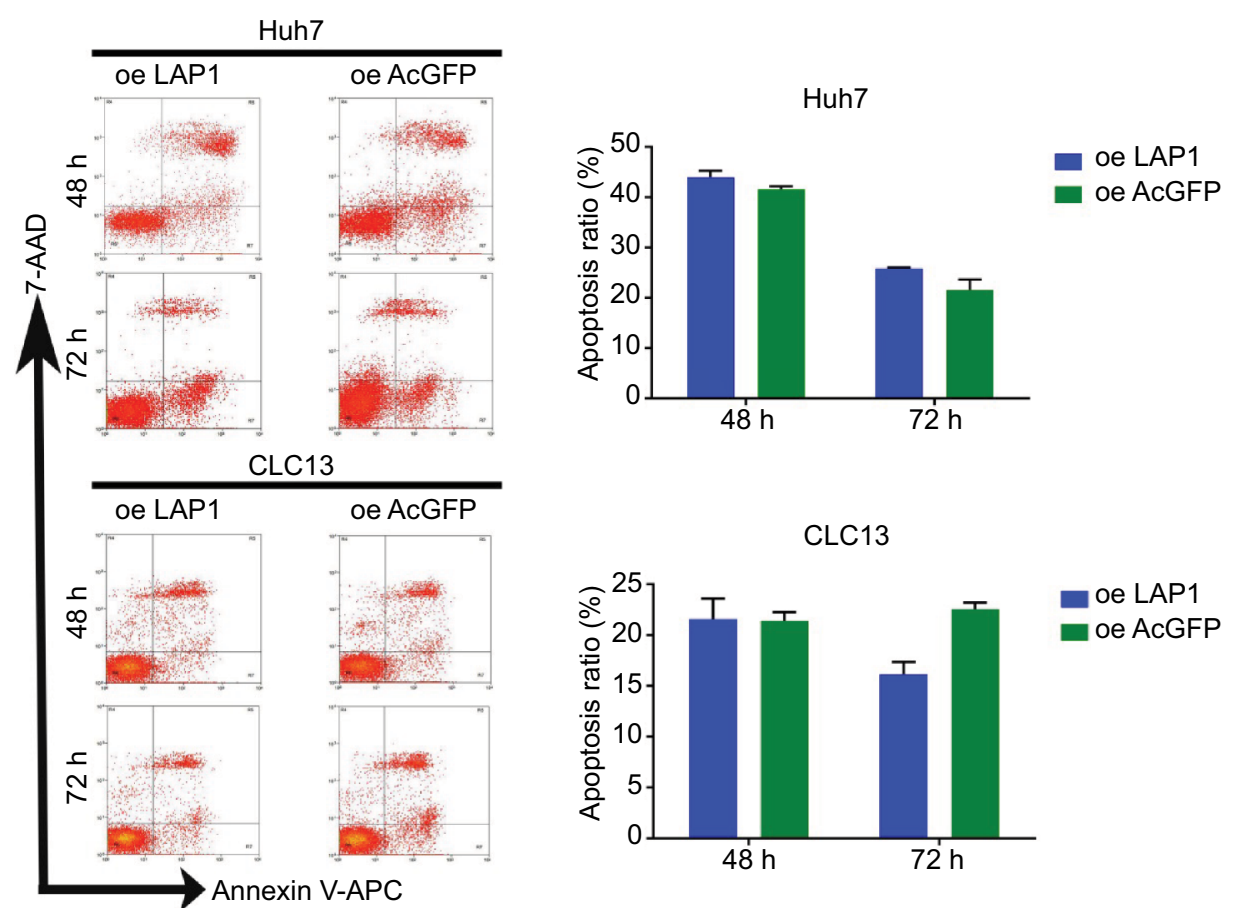

Figure SI After infection by LAPI and AcGFP for 48 and $72 \mathrm{~h}$, the cell apoptosis of Huh7 and CLCI 3 was examined. Cell apoptosis was not observed in both cells. The experiments were repeated three times, and representative data are shown. Each value represents the mean \pm SD for triplicate samples (Student's $t$-test). No significance $(P>0.05)$.

Abbreviations: LAPI, liver-enriched activator protein I; oe, overexpression.

Table SI Real-time PCR primers used in this study

\begin{tabular}{ll}
\hline Primers & Sequences \\
\hline GAPDH (forward) & 5'-CGACCACTTTGTCAAGCTCA-3' \\
GAPDH (reverse) & 5'-AGGGGTCTACATGGCAACTG-3' \\
CEBP 3 (forward) & 5'-CAAGAAGACCGTGGACAAGCA-3' \\
CEBP $\beta$ (reverse) & 5'-TCCACCTTCTTCTGCAGCC-3' \\
CDI3 (forward) & 5'-CAGAATTCAACTACGTGTGGA-3' \\
CDI3 (reverse) & 5'-ATTAATGATCTGTGCCCGAT-3' \\
CDI33 (forward) & 5'-CCACCGCTCTAGATACTGCT-3' \\
CDI33 (reverse) & 5'-ACATCATCGTACACGTCCTCC-3' \\
EPCAM (forward) & 5'-TGCACTTCAGAAGGAGATCACA-3' \\
EPCAM (reverse) & 5'-GTTCCCCATTTACTGTCAGGT-3' \\
\hline
\end{tabular}

Abbreviations: EPCAM, epithelial cell adhesion molecule; PCR, polymerase chain reaction.

Cancer Management and Research

\section{Publish your work in this journal}

Cancer Management and Research is an international, peer-reviewed open access journal focusing on cancer research and the optimal use of preventative and integrated treatment interventions to achieve improved outcomes, enhanced survival and quality of life for the cancer patient. The manuscript management system is completely online and includes

a very quick and fair peer-review system, which is all easy to use. Visit $\mathrm{http}: / / \mathrm{www}$.dovepress.com/testimonials.php to read real quotes from published authors. 